\title{
DAMPAK PEMBERIAN IMPULS ARUS TERHADAP TINGKAT PERLINDUNGAN ARRESTER TEGANGAN RENDAH
}

\author{
Diah Suwarti Widyastuti, Sugiarto
}

\author{
Teknik Elektro \\ Sekolah Tinggi Teknologi Nasional \\ Jalan Babarsari, Caturtunggal, Depok, Sleman, Yogyakarta \\ diah.w73@gmail.com
}

\begin{abstract}
Arrester is a device used to protect equipment and electrical systems against overvoltage that one reason is the surge of lightning. Because lightning is a natural phenomenon that the process can not be predicted about time and magnitude of the impulse currents, and if arrester hit by lightning impulse with high peak current value and than arrester is feared can not operate as it should. This research use three impulse current peak value there are $533.33 \mathrm{~A}(0.03 \mathrm{pu}), 3866.6 \mathrm{~A}(0.3 \mathrm{pu})$ and $6858.7 \mathrm{~A}(0.5 \mathrm{pu})$ tested at low voltage arresters. The test results shown the highest value of leakage current arrester at a maximum voltage of operation $\left(U_{c}\right)$ after buffeted by the current impulse has a value of leakage current $0,32 \mathrm{~mA}, 0,33 \mathrm{~mA}$ and $0,33 \mathrm{~mA}$ respectively, still below $1 \mathrm{~mA}$ (corresponding international standard IEC 61643-1 Edition 2.0 03/2005). Based on the value of leakage current, it can be said that the arresters in good condition and have not changed the characteristics of volt-ampere (current leaking still relatively the same) and still have good insulating properties even after the current impulse overwritten. The highest value of residual voltage arresters at the peak impulse voltage $10 \mathrm{kV}, 15 \mathrm{kV}, 20 \mathrm{kV}$ and 24 $\mathrm{kV}$, is 1124 Volt meaning that the margin has exceeded the limit of endurance voltage VWI class (1000 Volts) amounted to 112.4\%, and not exceed the VW2 (2000 Volt) amounted to $43.5 \%$, according to ISO standard 04-7021.21-2004, arresters can be used to protect the electrical equipment with voltage endurance on VW2 class.
\end{abstract}

Keywords: low voltage arresters, current impulse, the level of protection.

\section{Abstrak}

Arester adalah peralatan yang digunakan untuk memproteksi peralatan dan sistem elektrik terhadap tegangan lebih yang salah satu penyebabnya adalah surja petir. Karena petir merupakan proses gejala alam yang terjadinya tidak bisa diprediksikan waktu dan besar impuls arusnya, dan jika arrester diterpa impuls petir dengan nilai puncak arus yang tinggi maka arrester dikhawatirkan tidak dapat beroperasi sebagaimana mestinya. Dalam penelitian ini tiga nilai puncak arus impuls yaitu 533.33A (0.03 pu), 3866.6A $(0.3 \mathrm{pu})$ dan 6858.7 A (0.5 pu) diujikan pada arrester tegangan rendah .Hasil pengujian terlihat nilai arus bocor tertinggi arester pada tegangan maksimum operasi $(\mathrm{Uc})$ setelah diterpa impuls arus mempunyai nilai arus bocor masing-masing $0.32 \mathrm{~mA}, 0.33 \mathrm{~mA}$ dan $0.33 \mathrm{~mA}$, masih dibawah $1 \mathrm{~mA}$ (sesuai Standar internasional IEC 61643-1 Edition 2.0 03/2005). Berdasarkan nilai arus bocor dapat dikatakan bahwa arrester dalam kondisi baik dan belum mengalami perubahan karakteristik 
volt-ampere (arus bocornya masih relatif sama) serta masih mempunyai sifat isolator yang baik walaupun telah diterpa impuls arus. Nilai tegangan residu tertinggi arrester pada tegangan impuls dengan puncak $10 \mathrm{kV}, 15 \mathrm{kV}, 20 \mathrm{kV}$ dan $24 \mathrm{kV}$ yaitu 1124 Volt, artinya margin sudah melebihi batas ketahanan tegangan klas VW1 (1000Volt) sebesar $112.4 \%$ dan belum melebihi klas VW2 (2000Volt) sebesar 43.5\%, menurut standard SNI 04-7021.212004, arrester dapat digunakan untuk melindungi peralatan listrik dengan ketahanan tegangan pada klas VW2.

Kata kunci: arester tegangan rendah, impuls arus, tingkat perlindungan.

\section{Pendahuluan}

Surja petir dapat menimbulkan tegangan lebih dan dapat menyebabkan kerusakan pada jaringan tegangan rendah dan peralatan listrik tegangan rendah dengan beberapa mekanisme. Mekanisme pertama melalui sambaran petir langsung pada jaringan tegangan rendah. Mekanisme kedua adalah sambaran petir yang tidak langsung mengenai jaringan tegangan rendah tapi petir menyambar pohon ataupun tanah di sekitar jaringan tegangan rendah. Sambaran tidak langsung ini menyebabkan kopling elektromagnetik antara jaringan dan sambaran petir sehingga mengakibatkan tegangan induksi pada jaringan (Zorro, 2009)

Mengingat semakin besar jumlah kerusakan yang ditimbulkan oleh surja petir karena semakin banyaknya pemakaian komponen elektronik oleh masyarakat luas dan industri maka diperlukan sistem proteksi petir yang mampu melindungi peralatan tegangan rendah. Arrester adalah peralatan yang digunakan untuk memproteksi peralatan dan sistem elektrik terhadap tegangan lebih yang salah satu penyebabnya adalah surja petir. Arester tegangan rendah pada umumnya terbuat dari bahan ZnO (Zorro, 2009).

Ketahanan suatu peralatan memikul tegangan surja petir, jika dipasang pada suatu sistem bertegangan tertentu disebut BIL (Basic Impuls Level). Untuk setiap peralatan yang akan dipasang pada sistem tersebut selisih $\mathrm{BIL}$ peralatan yang dilindungi dengan tingkat proteksi arrester yang melindunginya disebut margin. Margin biasanya ditetapkan $(20-30 \%)$ dari BIL peralatan yang dilindungi. Penelitian ini dilakukan untuk mengetahui tingkat perlindungan arester terhadap peralatan yang dilindungi apabila arester tersebut diterpa oleh beberapa buah cacah impuls.

\section{Landasan Teori}

\subsection{Petir}

Petir merupakan proses alam yang terjadi di atmosfer yang mungkin terjadi sebelum dan pada saat terjadi hujan (thunder strom). Muatan akan terkonsentrasi di dalam awan atau bagian dari awan dan muatan yang yang berlawanan akan timbul pada permukaan tanah di bawahnya. Apabila muatan bertambah, beda potensial antara awan dan tanah akan naik sehingga kuat medan di udarapun akan naik. Jika kuat medan ini melebihi kuat medan diantara awan-awan tersebut maka akan terjadi pelepasan muatan. Kuat medan yang diperlukan untuk memulai aliran (streamer) adalah $\mathrm{E}_{\mathrm{B}}=10-40 \mathrm{kV} / \mathrm{m}$, pada awan yang mempunyai ketinggian $1-2 \mathrm{~km}$ diatas tanah dapat menghasilkan tegangan $100 \mathrm{MV}$ (Sirait, 1987) 


\subsection{Proses terjadinya petir}

Sambaran diawali oleh kanal muatan negatif, menuju daerah yang terinduksi positif dan sambaran yang terjadi umumnya adalah sambaran muatan negatifdari awan ke tanah. Tahapan sambaran petir diperlihatkan pada Gambar 1.

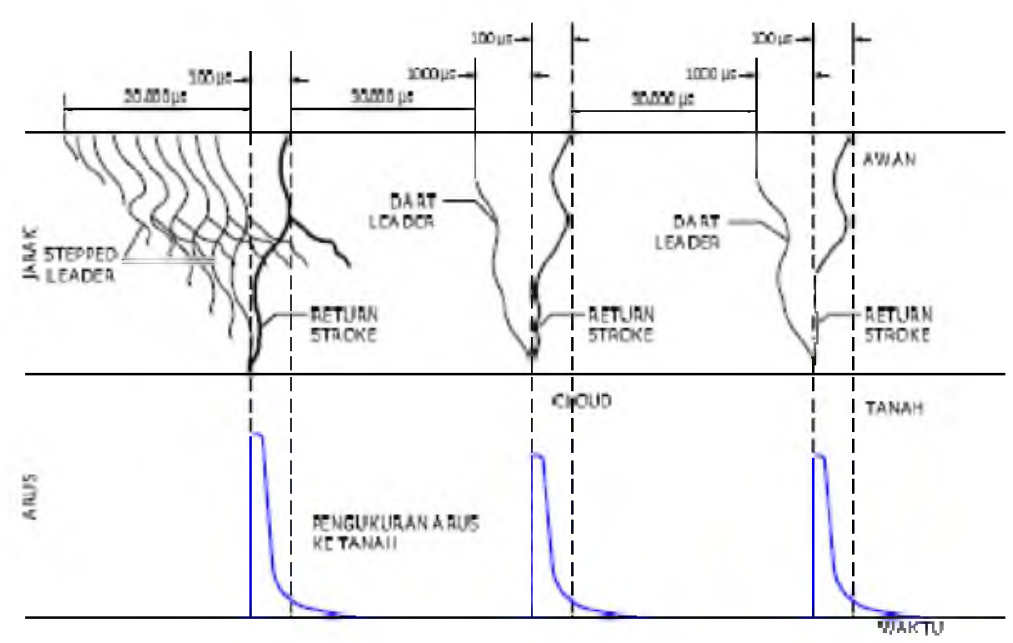

Gambar 1. Tahapan sambaran petir ke tanah dan arus impuls yang terjadi ( Sirait, 1987, Proteksi sistem tenaga)

\subsection{Arester}

Arester merupakan peralatan yang didesain untuk melindungi peralatan lain dari tegangan surja (baik surja hubung maupun surja petir) dan pengaruh arus susulan (follow curren). Sebuah arester harus mampu bertindak sebagai isolator, mengalirkan beberapa miliamper arus bocor ke tanah pada tegangan sistem dan berubah menjadi konduktor yang sangat baik, mengalirkan ribuan amper arus surja ke tanah (PLN, 2010)

\subsubsection{Arester tegangan Rendah MOV (Metal Oxide Varistor)}

Arester surja jenis MOV didesain tanpa menggunakan celah (gapless). Arester jenis MOV merupakan arester yang banyak diterapkan pada sistem tegangan rendah, karena memiliki rating arus pelepasan sebesar $1 \mathrm{kA}$ hingga $15 \mathrm{kA}$. Sebuah arester terbuat dari beberapa buah keping varistor yang memiliki nilai kapasitans berkisar 0,2-10 nF. Kecuali itu biasanya varistor juga memiliki induktans seperti terlihat pada Gambar 3.

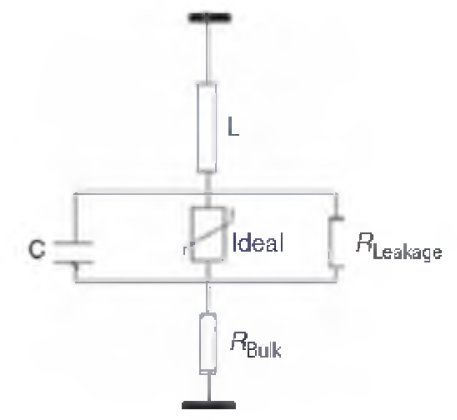

Gambar 2. Model rangkaian ekivalen dari varistor (Cooray, 2010). 
Berdasarkan Standar internasional IEC 61643-1 Edition 2.0 (03/2005) mendefinisikan karakteristik dan tes untuk Surge Protection Device pada sistem distribusi tegangan rendah seperti diperlihatkan pada Gambar 3.

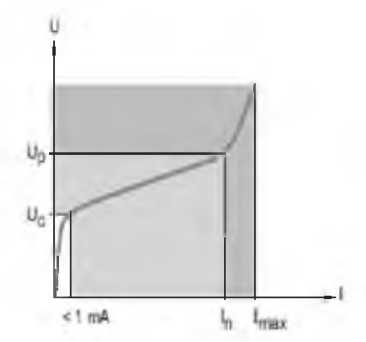

Gambar 3. Karakteristik arus/ waktu dari sebuah SPD dengan varistor (Schneider, 2010)

\subsubsection{Pembangkit arus impuls berulang $8 / 20 \mu$ detik}

Pembangkit arus impuls berulang ini dirancang dengan menggunakan struktur koaksial. Ketika pembangkit arus impuls ini beroperasi, Gambar 4, arus mengalir dari kapasitor melalui sela bola menuju ke plat kuningan atas lalu menyebar secara sentrifugal menuju ke jeruji-jeruji batang kuningan. Di jeruji-jeruji kuningan arus mengalir ke bawah menuju ke plat kuningan bawah. Kemudian arus ini mengalir melalui syant arus, dan kembali ke atas kembali ke kapasitor. Arus yang mengalir melalui jeruji-jeruji kuningan mempunyai arah yang sama dan berlawanan dengan arah arus yang melalui bagian tengah struktur koaksial. Akibatnya medan magnit yang disebabkan oleh struktur koaksial ini akan saling menghilangkan, sehingga diperoleh fluks magnit yang nilainya nol, atau bernilai sangat kecil sekali. Oleh karena itulah, induktans struktur koaksial pembangkit arus impuls ini rendah sekali. Menurut hasil ukur, induktans struktur koaksial pembangkit arus impuls ini adalah 2 $\mu \mathrm{H}$. Karena induktans yang kecil sekali, maka gelombang arus impuls yang dihasilkan tidak mengandung komponen frekuensi tinggi. Dengan demikian dapat dibangkitkan lima buah arus tinggi impuls dengan selang waktu diantaranya yang dapat diatur dengan menggunakan program komputer (Haryono).

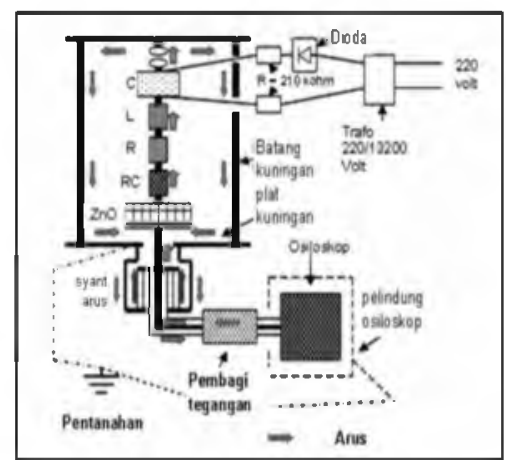

Gambar 4. Alir arus impuls di pembangkit arus impuls

\subsubsection{Margin}

Ketahanan suatu peralatan memikul tegangan surja petir, jika dipasang pada suatu sistem bertegangan tertentu disebut BIL (Basic Impuls Level). Untuk tegangan sistem tertentu, telah ditetapkan BIL dari setiap peralatan yang akan dipasang pada sistem tersebut. Selisih BIL peralatan yang dilindungi dengan tingkat proteksi arrester yang melindunginya 
disebut margin. Margin biasanya ditetapkan $(20-30 \%)$ dari BIL peralatan yang dilindungi (Tobing, 2003)

\subsubsection{Ketahanan Peralatan Listrik terhadap Surja}

Ketahanan peralatan listrik terhadap tegangan residu arester berbeda-beda yang didasarkan oleh Standar Nasional Indonesia (SNI) 04-7021.2.1-2004, tentang Peralatan dan Sistem Telekontrol, yang dispesifikasikan oleh IEC 60 dan IEC 664-1. Syarat minimum tegangan tahanan isolasi untuk peralatan dengan uji ketahanan frekuensi daya $50 \mathrm{~Hz}$ dan uji impuls ditentukn oleh Tabel 1 dengan beberapa ketentuan:

1. Uji tegangan dilakukan pada terminal masukan jalur daya, jalur komunikasi dan jalur kendali yang terisolasi dan jalur sinyal semua terminal yang tidak diuji harus dibumikan.

2. Rangkaian yang tidak diuji isolasinya harus dispesifikasikan oleh pembuatnya.

Tabel 1. Klas ketahanan tegangan

\begin{tabular}{|c|c|c|}
\hline Klas & $\begin{array}{c}\text { Ketahanan tegangan frekuensi daya } \\
(\mathrm{kV} \mathrm{rms}-60 \mathrm{~s})\end{array}$ & $\begin{array}{c}1,2 / 50 \mu \text { s tegangan impulse } \\
(\mathrm{kV} \text { puncak })\end{array}$ \\
\hline VW1 & 0,5 & 1 \\
\hline VW2 & 1 & 2 \\
\hline VW3 & 2,5 & 5 \\
\hline VWx & Khusus & Khusus \\
\hline
\end{tabular}

Catatan:

1. KlasVW1 dan VW2 adalah untuk peralatan yang beroperasi pada tegangan DC dibawah $60 \mathrm{~V}$. Klas VW2 dan VW3 adalah untuk pasokan tegangan sampai dengan $250 \mathrm{~V}$.

2. Nilai di atas disesuaikan dengan kondisi atmosfer standar. Faktor koreksi yang tepat mengacu pada IEC 60 yang diperoleh dari hasil pengujian pada kondisi yang berbeda-beda.

Pada terminal yang dilindungi oleh kapasitor yang dibumikan, uji catu daya frekuensi dapat diganti dengan DC pada tegangan yang sama dengan tegangan puncak dari tegangan $\mathrm{AC}$ (Haryono).

\section{Metodologi Penelitian}

Metode Penelitian dilakukan dengan melakukan pengujian pada Arester tegangan rendah merek Shihlin, type BHP40 dengan memberikan impuls arus dengan nilai puncak arus impuls sebesar 533.33 A (0.03 pu), 3866.6A (0.3 pu) dan 6858.7A (0.5 pu) untuk mengetahui dampak pemberian Impuls Arus terhadap tingkat perlindungan arrester tegangan rendah dalam upaya melindungi peralatan listrik tegangan rendah. Penelitian ini menggunakan metode perbandingan, yaitu membandingkan arus bocor arrester sebelum maupun setelah diterpa impuls dengan nilai yang ada pada Standar Internasional IEC 61643-1 Edition 2.0 (03/2005). Selanjutnya dengan memberikan tegangan impuls dengan puncak impuls $10 \mathrm{kV}$, $15 \mathrm{kV}, 20 \mathrm{kV}$ dan $24 \mathrm{kV}$ akan didapatkan tegangan residu arrester dan dapat memberikan informasi margin/ tingkat ketahanan arrester yang diuji.

\section{Hasil Penelitian dan Pembahasan}

\subsection{Hasil Analisis Arus Bocor arester}

Nilai arus bocor pada tegangan operasi maksimum $U_{c}$ setelah arester diterpa impuls arus dengan puncak arus $533.33 \mathrm{~A}(0.03 \mathrm{pu}), 3866.6 \mathrm{~A}(0.3 \mathrm{pu})$ dan $6858.7 \mathrm{~A}(0.5 \mathrm{pu})$ berturut- 
turut adalah $0.32 \mathrm{~mA}, 0.33 \mathrm{~mA}$ dan $0.33 \mathrm{~mA}$ diperlihatkan pada Gambar 5. Gambar 6 dan Gambar 7, menunjukkan bahwa setelah diterpa impuls arus arester masih belum mengalami degradasi dan masih bersifat sebagai isolator yang baik. Hal ini dikarenakan arus bocor arester masih dibawah nilai bakunya $(<1 \mathrm{~mA})$.

\subsection{Hasil analisis Tegangan Pemotongan Arester}

Nilai tertinggi tegangan pemotongan arester ketika diterpa tegangan impuls dengan puncak tegangan $10 \mathrm{kV}, 15 \mathrm{kV}, 20 \mathrm{kV}$ dan $24 \mathrm{kV}$, setelah diterpa impuls arus mempunyai tegangan pemotongan arrester/ tegangan residu tertinggi 1124.5 volt. Nilai tegangan pemotongan arester tersebut sudah melebihi batas ketahanan tegangan klas VW1 d belum melebihi batas ketahanan tegangan klas VW2 pada standar SNI 04-7021.21-2004. Artinya tegangan pemotongan arester masih di bawah standar klas VW2 namun sudah melebihi standar klas VW2. Artinya tegangan pemotongan arester dalam batas aman untuk peralatan listrik yang beroperasi di bawah 250 volt pada klas ketahanan VW2. Grafik tegangan pemotongan diperlihatkan pada Gambar 8.

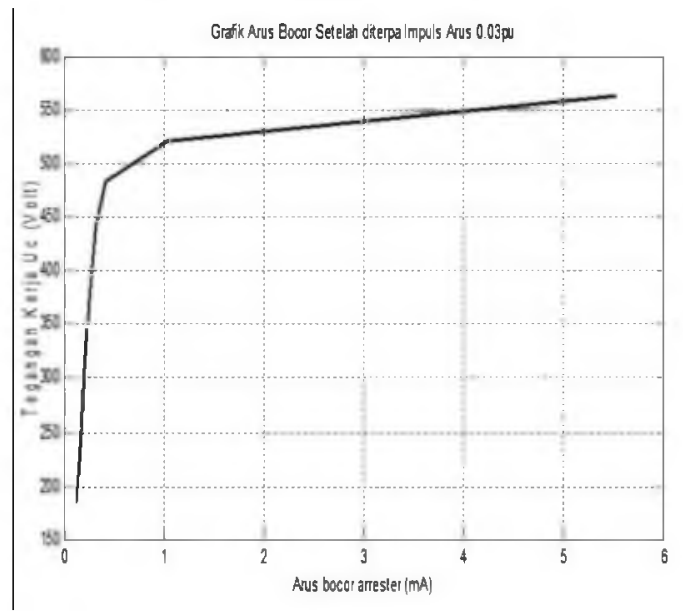

Gambar 5. Grafik Arus bocor Arrester setelah dikenai impuls arus dengan puncak 003pu

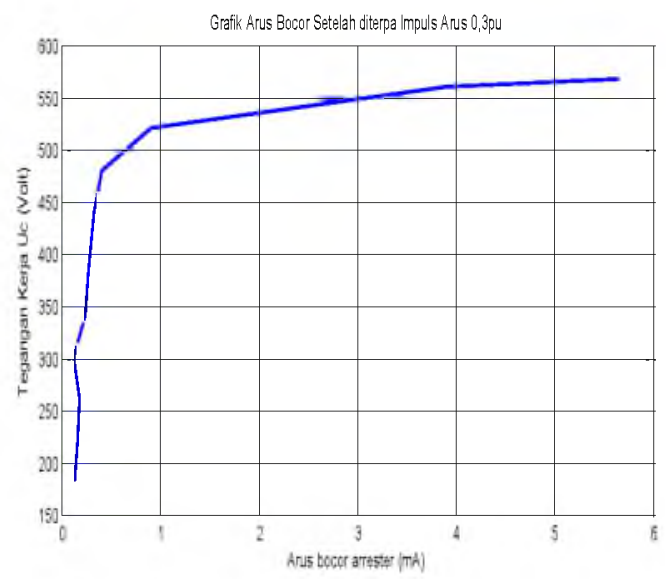

Gambar 6. Grafik Arus bocor Arrester setelah dikenai impuls arus dengan puncak 0,3pu 


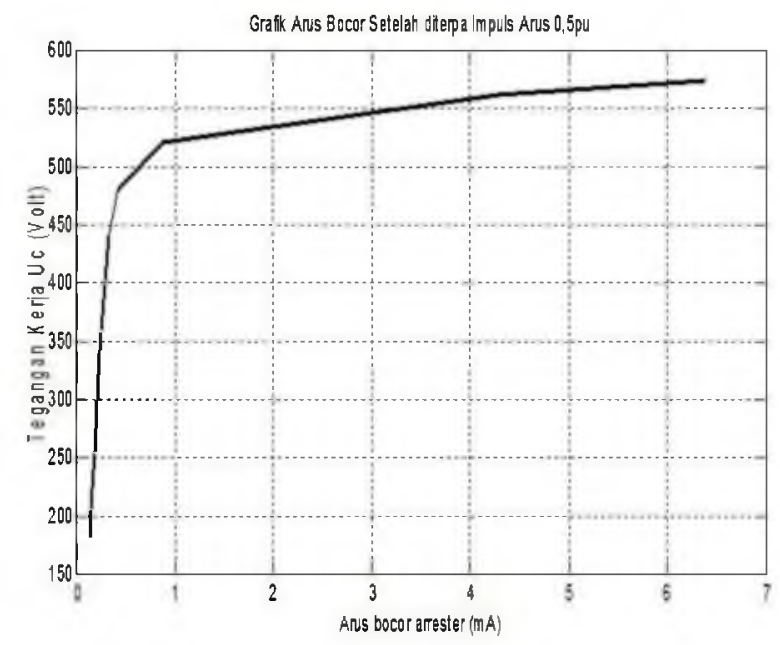

Gambar.7 Grafik Arus bocor Arrester setelah dikenai impuls arus dengan puncak 0,5pu

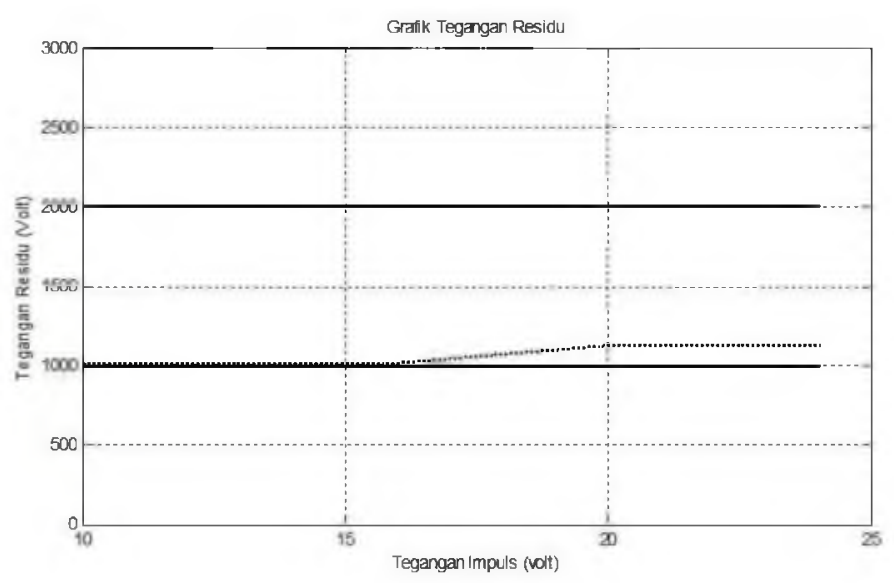

Gambar 8. Grafik tegangan residu arester

\subsection{Hasil Analisis Tingkat Ketahanan /Margin Arester}

Selisih BIL peralatan yang dilindungi dengan tingkat proteksi arester yang melindungi (Margin) biasanya ditetapkan (20 -30 dari BIL peralatan yang dilindungi.

\subsubsection{Untuk batas ketahanan tegangan klas VW1 (1000 volt)}

Selisih BIL peralatan yang dilindungi dengan tingkat proteksi arester yang melindungi adalah : 1000 volt -1124 volt $=-124$ volt. Dapat dikatakan bahwa -124 volt adalah 112,4\% dari BIL peralatan yang dilindungi, hal ini berarti margin arester untuk peralatan yang beroperasi pada tegangan DC di bawah 60 volt dapat dikatakan melebihi BIL peralatan yang dilindungi sebesar $12,4 \%$. Artinya $V_{\text {pemotongan }}>$ BIL peralatan sehingga Margin perlindungan peralatan melebihi yang ditentukan $(20 \%$ sampai dengan $30 \%$ BIL peralatan).

\subsubsection{Untuk batas ketahanan tegangan klas VW2 (2000 volt)}

Selisih BIL peralatan yang dilindungi dengan tingkat proteksi arrester yang melindungi adalah 2000 volt -1124 volt $=876$ volt. Margin arrester untuk peralatan listrik yang beroperasi di bawah 250 volt misalkan computer, arrester, stereo dan sebagainya adalah $43,8 \%$ dari BIL peralatan yang dilindungi, hal ini berartimargin pada arrester besar. Grafik margin perlindungan tegangan residu arrester diperlihatkan pada Gambar 9. 


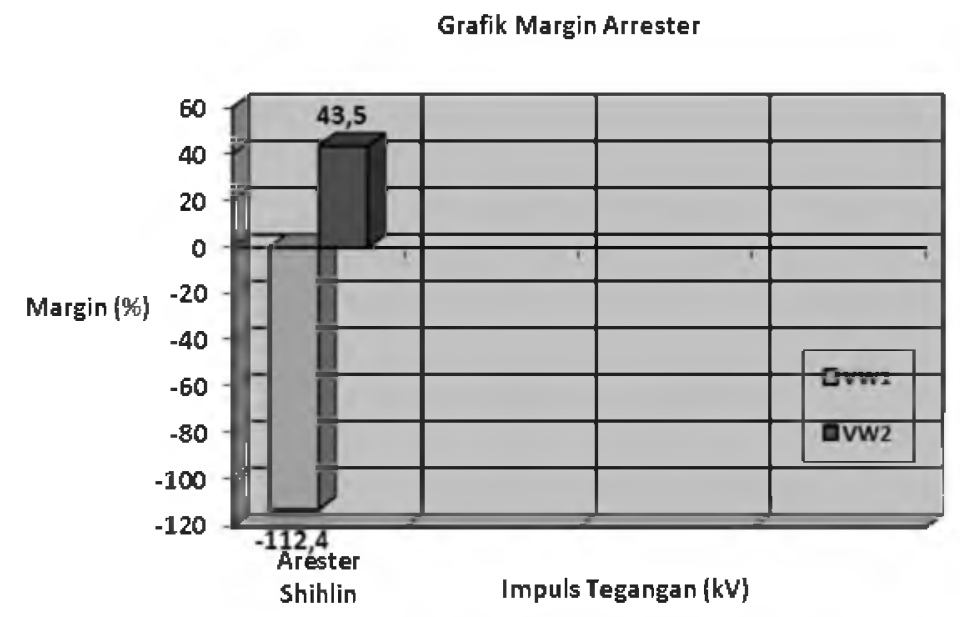

Gambar 9 Grafik margin perlindungan tegangan residu 82Arrester

Berdasarkan Gambar 9 dapat dikatakan bahwa semakin besar cacah impuls yang diterpakan pada arester maka selisih antara Basic Insulated Level (BIL) peralatan yang dilindungi dengan tingkat proteksi arester yang melindunginya (Margin) menjadi semakin kecil. Artinya semakin kecil nilai margin $(<20 \%)$ dari BIL peralatan yang dilindungi, semakin membahayakan peralatan yang dilindungi (watak kerja arester sudah mulai menurun). Hal ini juga dapat dikatakan bahwa alat yang diuji dapat digunakan untuk peralatan listrik yang mempunyai klas ketahanan tegangan 2000 volt. Untuk peralatan listrik yang mempunyai klas ketahanan tegangan 1000 volt memerlukan pertimbangan untuk memakai alat ini. Hal ini dikarenakan tegangan pemotongan sudah melebihi standar yang ditetapkan oleh SNI sehingga dapat membahayakan bagi peralatan listrik yang dilindunginya.

\section{Kesimpulan}

Berdasarkan hasil penelitian dan pembahasan yang telah dilakukan maka dapat diambil kesimpulan sebagai berikut:

1. Nilai tegangan residu tertinggi arrester Sihlin pada tegangan impuls dengan puncak $10 \mathrm{kV}$ s.d $24 \mathrm{kV}$ yaitu 1124 Volt yaitu 1124 volt, sudah melebihi batas ketahanan tegangan klas VW1 dan belum melebihi klas VW2 menurut standard SNI 04-7021.21-2004. Menurut SNI BIL peralatan listrik tegangan rendah adalah 1000 volt untuk klas VW1 dan 2000 volt untuk klas VW2.

2. Nilai arus bocor tertinggi arester pada tegangan maksimum operasi (Uc) setelah diterpa impuls arus dengan puncak $0.03 \mathrm{pu}, 0.3 \mathrm{pu}$ dan 0.5 pu masing-masing $0.32 \mathrm{~mA}, 0.33$ $\mathrm{mA}$ dan $0.33 \mathrm{~mA}$, masih dibawah $1 \mathrm{~mA}$ (sesuai Standar internasional IEC 61643-1 Edition 2.0 03/2005). Dalam hal ini arester masih dikatakan dalam kondisi baik dan belum mengalami perubahan karakteristik volt-ampere (arus bocornya masih relatif sama) serta masih mempunyai sifat isolator yang baik walaupun telah diterpa impuls arus.

3. Arester yang diuji pada penelitian ini cocok digunakan pada peralatan listrik dengan BIL peralatan 2000 volt. Penggunaan arrester dengan BIL peralatan 1000 volt tidak disarankan karena tegangan residu masih sudah diatas 1000 volt sehingga margin yang dihasilkan $>20 \%$ sehingga dapat membahayakan peralatan yang dilindungi. 


\section{Daftar Pustaka}

,2004, Peralatan dan Sistem Telekontrol, Standart Nasional Indonesia (SNI)

2010, Overvoltage protection, Chapter J, Schneider Electric - Electrical installation guide 2010

Cooray V., 2010, Lightning Protection, Institution of Engineering and Technology, London, United Kingdom

Haryono T., Karya Unggulan Pembangkit Arus Tinggi

PLN, 2010, Petunjuk Operasi \& Pemeliharaan Lightning Arester, Operation Manual, PLN.

Sirait \& Zorro., 1987, Proteksi Terhadap Tegangan Lebih, Jurusan Teknik Elektro FTI ITB.

Tobing L.B., 2003, Peralatan Tegangan Tinggi, PT Gramedia Pustaka Utama.

Zoro R., 2009, Induksi dan Konduksi Gelombang Elektromagnetik akibat sambaran petir pada Jaringan Tegangan Rendah, Makara Teknologi Vol. 13 No. 1, April 2009: 2532. 
Diah Suwarti Widyastuti, Sugiarto 